* Doutor em Ciências Jurídicas pela Universidade Federal da Paraíba. Mestre em Ciências Jurídicas pela Universidade Federal da Paraíba. Especialista em Direito tributário pela Universidade do Sul de Santa Catarina (UNISUL). Bacharel em Direito pelo Centro Universitário de João Pessoa.

Email: bbastos.adv@gmail.

com

**Mestrando em Direito pela Universidade de Marília. Bacharel em Direito pela Faculdade de Ciências Gerenciais de Dracena.

Email:jeffersonpgerminari@ gmail.com

\section{Compliance Fiscal: Diminuição De Riscos \\ E Aumento De Competitividade No Mundo \\ Corporativo.}

\author{
TaX Compliance: Risk Reduction And InCREASED \\ COMPeTITIVEness In The CORPORATE World
}

\section{Bruno Bastos de Oliveira* Jefferson Patrick Germinari**}

Como Citar: OLIVEIRA, Bruno Bastos de. GERMINARI, Jefferson Patrick. Compliance fiscal: diminuição de riscos e aumento de competitividade no mundo corporativo. Scientia Iuris. Londrina, v.24, n.1, p. 78-98, março 2020. DOI 10.5433/21788189.2020v24n1p78. ISSN 2178-8189.

Resumo: Os programas de compliance são cada vez mais difundidos, especialmente no âmbito do setor privado, permitindo-se que as organizações se coloquem em conformidade com questões jurídicas e consequentemente haja gradativo aumento na eficiência. $\mathrm{O}$ objetivo do presente artigo é analisar o compliance, em especial o inserido no âmbito fiscal, na perspectiva do ordenamento jurídico nacional, além de verificar os impactos da adoção desses mecanismos como forma de ganho de competitividade, sendo utilizado o método dedutivo de pesquisa, com coleta de bibliografia temática. Conclui-se que a prática da conformidade, em especial o compliance fiscal, figura-se instrumento fundamental à minimização de riscos e aumento da competitividade, especialmente pelo ganho de confiabilidade de ambiente pautado na integridade e na segurança de investimentos.

Palavras-chave: Compliance. Compliance fiscal. Eficiência. Competitividade.

Abstract: Compliance programs are becoming increasingly widespread, especially in the private sector because they facilitate the observance of legal norms; consequently, companies are becoming more complicit. The main aim of this paper is to analyze compliance, especially in the context of tax law, from the perspective of the Brazilian legal system. Moreover, this study verifies the impacts of these mechanisms as a means for having a competitiveness advantage. In order to accomplish this 
important objective, this article used the deductive method and literature review. Finally, this paper concludes that compliance, particularly tax compliance, is fundamental in reducing risks and increasing competitiveness, especially because it creates a safe and reliable environment for investments

Keywords: Compliance. Tax Compliance. Efficiency. Competitiveness. 


\section{INTRODUÇÃO}

Os países que apresentam grau de percepção de integridade mais elevado localizam-se nas regiões mais desenvolvidas do planeta, em especial, na América do Norte e na Europa, enquanto regiões afetadas por grande instabilidade encontram-se em zonas de altos índices de corrupção.

O Brasil encontra-se em um estágio preocupante, especialmente por ser fato que a riqueza e potencial econômico deveriam gerar um parâmetro de estabilidade mais efetivo, com vistas a estimular o desenvolvimento nacional através de um setor privado forte e competitivo.

A confiabilidade corporativo-institucional é fator preponderante tanto à prosperidade governamental, no estabelecimento de acordos mundiais e busca por capital e investimento estrangeiro, que influi diretamente no crescimento econômico e desenvolvimento do país, como ao destaque empresarial e respectiva sustentação num mercado concorrencial tão impiedoso. Empresas em caminhos limpos, que cumprem suas metas, obedecem ao ordenamento jurídicolegal, comprometidas com a responsabilidade social e políticas públicas, têm passagem garantida à ascensão econômica.

Diante da necessidade de dar azo à conformidade corporativa, sejam nas demandas internas, sejam externas, a origem do compliance tem por inspiração tomadas éticas e de comprometimentos inclinados à prevenção de riscos, minimização de oneração e otimização de condutas por melhores resultados, que em seu conjunto favorecem à permanência dos empreendimentos no mercado concorrencial, por vezes, à frente daqueles que ignoram tal ideologia.

Numa abordagem científica em linha de pesquisa metodológica dedutiva, objetiva-se analisar as bases fundamentais do compliance, em estudo acerca da corrupção e do arcabouço legal de repressão a tais práticas, em especial a Lei 12.846/2013 (BRASIL, 2013), com vista derradeira quanto aos benefícios indiscutíveis que o compliance fiscal e o planejamento tributário, eficientemente, são capazes de proporcionar no âmbito organizacional, especialmente no que tange à competitividade organizacional.

No presente artigo aplicou-se técnicas de pesquisa bibliográfica, com técnicas de categorização aos artigos científicos disponíveis nos principais indexadores da área. No processo de busca dos artigos, utilizaram-se as palavras-chave com auxílio do mecanismo de filtragem, ficando a seleção dos artigos limitada àqueles em que as mesmas se encontrassem presentes.

\section{CORRUPÇÃO E COMPLIANCE: BREVE ESCORÇO HISTÓRICO NO CONTEXTO DA LEI 12.846/2013}

Compreender o funcionamento da espinha dorsal onde se alojam fundamentos tantos que promoveram as transformações empresariais no contexto atual, inspirados pelo compliance, coloca-se por imprescindível, antes de se imergir noutras aberturas indiscutivelmente influenciadas por essa força de conduta motriz de higidez.

Tal sistemática teve por objeto inaugural a prevenção de práticas de corrupção, perfazendo 
"um complexo fenômeno global que advém de fatores econômicos, institucionais, políticos, sociais e históricos" (HAYASHI, 2014, p.16), depreendendo-se daí diversas manifestações de ordem pública, privada e social, o que afetou o processo de desenvolvimento em todos os países do mundo, independentemente do regime ou dos sistemas econômicos o qual estejam vinculados.

Ferreira Filho (1991, p. 2) esclarece que muitos são os sentidos nos quais a corrupção pode ser compreendida, sendo uníssona a ideia de uma conotação pejorativa. Etimologicamente, "o termo vem do latim corruptio, cujo sentido próprio é 'deterioração, alteração', cujo sentido figurado é 'depravação', isto é, 'corrupção'. O verbo correspondente é corrumpere, que, no sentido próprio, quer dizer 'rebentar', ou 'fazer rebentar'”, e quando levado ao "sentido figurado, significa 'estragar, adulterar, deteriorar, corromper"'.

Gabardo e Morettini e Castella (2015, p. 130) esclarecem que a corrupção é um fenômeno bastante complexo, "passível de análise a partir de múltiplas perspectivas. Independente do fato de não existir conceito jurídico acerca do que, efetivamente, consiste a corrupção, parece haver um forte consenso de que ela é um ato portador de grande nocividade", capaz de influenciar todas as dimensões de estrutura orgânica do Estado, como também todas as esferas da organização política, social e econômica, fatores indispensáveis e coadjuvantes ao desenvolvimento.

A corrupção-suborno possui um episódio histórico, a obra Bribes, de John T. Noonan Junior (1989), que trata do induzimento por interesse próprio capaz de influenciar a função pública com o objetivo de obtenção de uma retribuição material, praticada de diversas maneiras. Dentre os fatores estimulantes à corrupção tem-se a ideia que resulta do individualismo utilitarista para obtenção da vantagem para si, seja qual for o meio; outro é o interesse material, visto como "mola da vida e do homem, não passando de hipocrisia e de aparência o idealismo, o civismo, a moralidade, etc.” (FERREIRA FILHO, 1991, p. 7). Quanto à segunda dimensão de corrupção, favorecimento, é bastante utilizada em zonas onde a dicotomia público-privada se encontra instalada e pouco definida, em que há manipulação do interesse público em face dos individuais, conjugados pela conveniência de circunstâncias que levam ao favorecimento em face de pretensões paralelas e por vezes escusas.

O suborno e o favorecimento são duas modalidades de ocorrência bastante reiterada, realizados inclusive por países hoje desenvolvidos, há época que se encontravam no seu processo de crescimento, exemplo dos Estados Unidos no século XVIII e da Inglaterra no século XIX; “o suborno tem uma história que se divide em períodos distintos. De aproximadamente 3000 a.C. a 1000 d.C., a ideia da não reciprocidade luta contra as normas de reciprocidade que cimentam sociedades cujos governantes são, ao mesmo tempo, juízes e receptores de oferendas." (NOONAN JUNIOR, 1989, p. 11).

Em âmbito nacional é possível detectar a existência de um plexo normativo voltado à tutela da moralidade, a citar, a Lei 8.429/1992 que trata acerca do combate à improbidade administrativa, a Lei 8666/1993 trazendo dentro do assunto ligado aos contratos administrativos e licitação reserva de cláusulas penais à transgressão, a Lei 11529/2011 que se refere à defesa da concorrência, a Lei Complementar no 135/2010 conhecida como Ficha Limpa, o Código Penal na 
previsão de condutas ligadas à relação pública, ou seja, nota-se certa preocupação à prevalência sadia das relações transacionais públicas e privadas.

Debruçando-se às ideias específicas do compliance, Assi (2018, p. 6-7) explica que o referido termo é próprio da língua inglesa, derivado do verbo to comply, podendo ser compreendido como cumprimento, obediência, execução consoante ao que fora determinado; sob a ótica empresarial "consiste no dever das empresas de promover uma cultura que estimule, em todos os membros da organização, a ética e o exercício do objeto social em conformidade com a lei”; no contexto corporativo, sócios, acionistas, administradores, fornecedores, clientes, dentre outros parceiros requerem "retidão e transparência das empresas, direcionando-as à remodelação de seus negócios com base nas melhores práticas de governança corporativa, exigindo-lhes maior cuidado no processo de tomada de decisão" (ASSI, 2018, p. 7).

Diante da experiência vivenciada pelo Brasil nos últimos anos em que se acentuou a discussão acerca do rompimento moral e da quebra da confiança institucional, por inspiração também de normas estrangeiras tais como o Ato de Prevenção de Corrupção Estrangeira, nos Estados Unidos, em 1977, o Ato contra a Corrupção em 2010, na Inglaterra, em adequação às exigências traçadas pela ONU e OEA, houve a necessidade de atos comissivos legais inclinados à instigação de mudanças de paradigmas; daí o advento da Lei 12.846/2013, conhecida como Lei Anticorrupção ou Lei da Empresa Limpa, na tentativa de amenizar os impactos negativos difundidos tanto na sociedade brasileira como na comunidade internacional, conferindo maior responsabilização administrativo-civil às pessoas jurídicas que eventualmente pratiquem ações lesivas contra a Administração Pública.

A Lei Anticorrupção se sustenta, pela leitura do caput do artigo $5^{\circ}$, na defesa de três grandes dimensões ligadas à Administração Pública, quais sejam, o patrimônio público nacional ou estrangeiro, os princípios da Administração Pública e os pactos internacionais dos quais o Brasil seja signatário. A ideologia do compliance encontra-se consolidada no inciso IX do artigo $7^{\circ}$, na medida em que sopesa, na aplicação das sanções correspondentes, eventual existência de mecanismos e procedimentos internos de integridade, auditoria e incentivo à denúncia de irregularidades e a utilização efetiva de códigos de ética e de conduta no âmbito da pessoa jurídica. Deste modo, tal premissa torna-se mais um mecanismo, dentre as inúmeras ferramentas disponíveis, voltado ao movimento solidário de combate à corrupção e da política do oportunismo que estão impregnados na cultura nacional, em todas as esferas, pública ou privada, em respeito à voz da moralidade institucional que ecoa em nosso país.

\section{GENERALIDADES, ORIGEM E NOVAS DIMENSÕES SOBRE O COMPLIANCE}

É possível afirmar que o compliance no contexto moderno foi externalizado aos mais diversos ambientes político-sociais, impondo cada vez mais às pessoas físicas e jurídicas, na esfera pública ou privada, postura conformadora pautada em valores e princípios tendentes à construção de uma sociedade coesa e digna. 
O Compliance no âmbito empresarial teve como inspiração a iniciativa de alinhamento globalizado lançado no ano 2000 pelo então secretário-geral da Organização das Nações Unidas, Kofi Annan, na operacionalização de dez princípios universais em área de Direitos Humanos, dentre eles a prerrogativa de que as empresas devem combater a corrupção em todas as suas formas, incluindo-se a extorsão e a propina. Tal pacto traçou base principiológica objetivando orientar empresas e funcionários a boas práticas de conduta inclinadas à promoção do crescimento sustentável.

Apesar de originariamente pautada em premissas anticorrupção e contra fraudes corporativas (GABAN; DOMINGUES, 2016, p. 344), o compliance também possibilitou o desenvolvimento de programas específicos em variadas áreas da atividade empresarial atingindo novos patamares. No esteio protetor de valores institucionais, encontra-se a preocupação de tutelas voltadas aos direitos humanos, uma vez que alinhadas às práticas éticas também estão as medidas preventivas ao trabalho infantil, escravo, vexatório com olhar a questões circulantes da órbita trabalhista e de satisfação do mercado consumidor.

Ferreira, Queiroz e Gonçalves (2018, p. 261-262) destacam tal qual aconteceu nos Estados Unidos com o WorldCom, a preocupação do setor empresarial a partir dos grandes escândalos de criminalidade econômica que deu origem na esfera Legislativa ao Sarbanes-Oxley Act de 2002; destacando-se também o caso SIEMENS, na Alemanha, com condenações em face das práticas de corrupção e deslealdade concorrencial. Santos (2011, p. 32) esclarece que o compliance empresarial originou-se nas instituições financeiras, em 1913, com o surgimento do Banco Central Americano, objetivando a estruturação de um sistema seguro, flexível e estável, e, logo após a quebra da Bolsa de Valores em Nova York, com a criação da política econômica intervencionista New Deal, propiciando oscilações típicas do ambiente capitalista.

As ideias de compliance perfazem-se na congruência de dois fatores, quais sejam, a busca por práticas éticas e um comando norteador correspondente; no cerne motivacional de tais medidas se alocam fatores fundamentais, se não essencialmente imprescindíveis, à regulação e ao desenvolvimento mercantil, haja vista que em meio a um ambiente competitivo, atuar propiciando ao consumo viés diferencial, de confiabilidade das relações econômicas e sociais, prevenindo-se contra riscos operacionais, reputam-se preponderantes à sobrevivência concorrencial.

Compreender tal inspiração como sujeição institucional a preceitos normativo-legais ao passo em que se dá importância merecida na melhor gestão e nos caminhos a serem percorridos por cada empresa, inserida num mercado concorrencial cada vez mais exigente, impiedoso e excludente - em que os valores da confiança consumista, a formação de novas alianças de mercado e a prevenção de sanções são fatores preponderantes ao sucesso - são premissas moduladoras inaugurais importantes que possibilitam, a partir daqui, analisar este instituto sob a ótica de outros setores da gestão corporativa.

\section{LEI ANTICORRUPÇÃO E OS IMPACTOS NO ESPAÇO CORPORATIVO}


Numa era tecnológica em que as informações e os procedimentos são processados em velocidade galopante, exige-se o compliance como ferramenta moduladora da atividade empresarial, uma vez que condutas desprezíveis do mercado negocial, quando divulgadas em larga escala - frisem-se ainda as distorções por fakenews - podem ser verdadeiras armadilhas que levam à derrocada do empreendedorismo.

Abreu Junior (2015, p. 26) menciona que o crescimento econômico, a estabilidade política como também a maior importância brasileira no contexto diplomático elevou a imagem do país internacionalmente, o que implicou no aumento da atenção organizacional externa a fatos ocorridos no Brasil. Assim, a corrupção corporativa/governamental que aflige a população "passa a impactar não comente a confiança da sociedade civil em seus governantes e organizações, como também prejudica a imagem brasileira em mercados internacionais."

Os escândalos internacionais como os acontecidos nos Estados Unidos, no ano de 2001, com as empresas Enron, Xerox, WorldCom e Arthur Andersen motivou a promulgação, no ano seguinte, da Lei Sarbanes Oxley, objetivando-se restabelecer o nível de confiança nas informações geradas pelas empresas em prol da consolidação teórica dos mercados eficientes que guiam os mercados de títulos e valores mobiliários por intermédio de aplicação de sanções a empresas praticantes de condutas avessas às boas práticas.

No mesmo sentido, os atos de corrupção envolvendo a empresa Petrobras no ano de 2013, propiciou o advento da Lei 12.846/13, sendo que em seu artigo $7^{\circ}$, pormenorizou, dentre outros fatores a serem levados em consideração na aplicação de sanções empresariais, em especial no seu inciso VIII, o compliance na efetivação de práticas éticas por intermédio de mecanismos e procedimentos internos de integridade, auditoria e incentivos à denúncia de irregularidades, bem como do proveito efetivo dos correspondentes códigos de ética e de conduta internos. Aliás, Marques $(2015$, p. 4) já salientava quanto à necessidade de criação de códigos de ética e condutas afins, no âmbito empresarial, para "implementar procedimentos padrões confiáveis e seguros, monitorar o desempenho e a postura profissional, fixar controles e planejamentos internos agindo com correção são apenas alguns dos métodos balizadores de um programa de compliance.”

Planos de conformidade propiciam aos empreendedores o abrandamento de eventuais sanções em face de imprevisíveis práticas vedadas que tenham sido praticadas em ambiente corporativo; empresas atuantes nesse viés proporcionam maior segurança jurídica e econômica aos seus investidores, angariando, por consequência, maior confiança de mercado.

Sob esta orientação o reflexo às relações contratuais entre empresas terceirizadas e fornecedores, cuja dinâmica visa amenizar as chances de se contratar com empresas intransigentes, eis que se depreende de tais operações a responsabilidade solidária integrada ao processo de produção coligado. Magalhães (2013, p. 31) explica ainda quanto à responsabilidade objetiva encabeçada no artigo $1^{\circ}$ da Lei 12.846/2013, sendo o compliance uma medida de resguardo aos dirigentes e administradores contra atos indesejados que estejam fora do alcance gestor.

No artigo $5^{\circ}$, incisos, da Lei $12.846 / 2013^{1}$, encontram-se elencados os atos considerados

1 Art. $5^{\circ}$ Constituem atos lesivos à administração pública, nacional ou estrangeira, para os fins desta Lei, todos 
lesivos à Administração Pública, objeto de tutela legal, sendo que no artigo $6^{\circ}$ do mesmo encartado estão descritas as sanções administrativas aplicadas às pessoas jurídicas; além da publicação extraordinária da decisão condenatória, a multa que oscila entre $0,1 \%$ e $20 \%$ do faturamento bruto do último exercício ao da instauração do processo administrativo, excluídos os tributos, o que demandam prejuízos significativos de receita com impactos inquestionáveis no que respeita à sua capacidade de investimento, melhorias corporativas, gastos com pessoal e futuras contratações.

Para além das sanções administrativas, a responsabilidade judicial estampada no artigo 19 da Lei 12.486/2013, pode implicar em perdimentos de bens, suspensão ou interdição parcial de suas atividades, dissolução compulsória e proibição de receber incentivos, subsídios subvenções, doações ou empréstimos de órgãos ou entidades públicas e de instituições financeiras públicas por prazo de até cinco anos.

Shirazi (apud ABREU JUNIOR, 2015, p. 28-29) menciona que a corrupção impacta, além da atratividade de capital estrangeiro para investimentos, o próprio desenvolvimento do comércio internacional, cuja competitividade inerente a todos os países, em especial aos emergentes, está relacionada ao volume do comércio e práticas corporativas corruptivas, tornando-se mais importante ainda a discussão acerca do tema, uma vez que o desenvolvimento do comércio internacional está relacionado à confiança de investidores.

Chega-se, por análise do ranking de Comércio Internacional e Indicador Global de Governança (WGI - Worldwide Governance Indicators) desenvolvido pelo Banco Mundial, ao ponto de concluir que o comércio internacional de países como Egito, Rússia e Ucrânia ser mais "positivamente impactado por medidas de combate à corrupção do que por ações visando a redução da carga tributária, adequações na legislação laboral ou, até mesmo, medidas de controle cambial" (SHIRAZI apud ABREU JUNIOR 2015, p. 29), dada a importância que a confiabilidade de condutas e a segurança econômica podem influenciar ao desenvolvimento setorial.

\section{PROGRAMAS DE COMPLIANCE E SUAS VÁRIAS APLICAÇÕES}

aqueles praticados pelas pessoas jurídicas mencionadas no parágrafo único do art. $1^{\circ}$, que atentem contra o patrimônio público nacional ou estrangeiro, contra princípios da administração pública ou contra os compromissos internacionais assumidos pelo Brasil, assim definidos:

I - prometer, oferecer ou dar, direta ou indiretamente, vantagem indevida a agente público, ou a terceira pessoa a ele relacionada;

II - comprovadamente, financiar, custear, patrocinar ou de qualquer modo subvencionar a prática dos atos ilícitos previstos nesta Lei;

III - comprovadamente, utilizar-se de interposta pessoa física ou jurídica para ocultar ou dissimular seus reais interesses ou a identidade dos beneficiários dos atos praticados;

IV - no tocante a licitações e contratos:

a) frustrar ou fraudar, mediante ajuste, combinação ou qualquer outro expediente, o caráter competitivo de procedimento licitatório público;

b) impedir, perturbar ou fraudar a realização de qualquer ato de procedimento licitatório público;

c) afastar ou procurar afastar licitante, por meio de fraude ou oferecimento de vantagem de qualquer tipo;

d) fraudar licitação pública ou contrato dela decorrente;

e) criar, de modo fraudulento ou irregular, pessoa jurídica para participar de licitação pública ou celebrar contrato administrativo;

f) obter vantagem ou benefício indevido, de modo fraudulento, de modificações ou prorrogações de contratos celebrados com a administração pública, sem autorização em lei, no ato convocatório da licitação pública ou nos respectivos instrumentos contratuais; ou

g) manipular ou fraudar o equilíbrio econômico-financeiro dos contratos celebrados com a administração pública (BRASIL, 2013). 
O plano ideológico do compliance difunde-se pelas mais diversas esferas do ambiente corporativo, numa visão de responsabilidade empresarial solidária em face das políticas públicas determinadas em atendimento a diversas exigências que correm paralelas, mas interligadas, ao mercado de consumo, atuando de modo a planificar projetos e conciliá-los à amenização de riscos e ao desenvolvimento eficiente, diante da base dúplice de custo-benefício alinhado a inúmeros vieses.

A partir daqui, o escopo do presente trabalho volta-se à abordagem do compliance nos mais variados campos, quais sejam, no administrativo, nas práticas trabalhistas, assim como o depreendido das tomadas de ordem ambiental e o fiscal, em visão inclinada a tais preceitos como coadjuvante institucional favorável ao sucesso organizacional, prevenindo-lhes riscos e evitando danos maiores que eventualmente possam obstacularizar empreendimentos e o seu correspondente crescimento.

Apesar de no âmbito da Administração Pública Direta não haver expressa determinação de práticas de compliance, maior empregado no âmbito privado, é possível notar significativo emaranhado legal de mesma inspiração, como ocorre na Lei de Improbidade Administrativa (Lei 8.429/92), no Decreto 5.480/2005, que implementa o Sistema de Correição do Poder Executivo Federal, a Lei de responsabilidade fiscal (Lei Complementar 101/20000), a Lei de Acesso à Informação (Lei 12.527/2011, o Decreto 1.171/1994 que estabelece o Código de Ética Profissional do Servidor Público Civil do Poder Executivo Federal e a Lei 12.813/2013, que cuida acerca dos conflitos de interesse do exercício de cargo ou emprego no âmbito do Poder Executivo Federal.

Ademais, é possível notá-lo em inúmeros pontos dos mais diversos Estatutos de serviços públicos estaduais; exemplo disso é a Lei paulista $\mathrm{n}^{\circ}$ 10.261/68 (Estatuto dos Funcionários Públicos Civis do Estado de São Paulo), onde em seu artigo 241, inciso XIII, determina aos servidores públicos o dever de estarem em dia com as leis, regulamentos, regimentos, instruções e ordens de serviço que digam respeito às suas funções. Dispõe também, no artigo 241, variados deveres de ordem ética a serem observados, em especial o de o servidor desempenhar atividades com zelo e presteza e o de representar aos superiores quaisquer irregularidades de que tiverem conhecimento, além dos elencados no artigo 242, incluindo-se a proibição de tratar interesses particulares na repartição e os expressos no artigo 243, em sua grande maioria voltados a vedações do exercício de atividades econômicas, tomando importância o expresso no inciso XI, que lhes incumbe a vedação de se valer de sua qualidade de funcionário para desempenhar atividade estranha às funções ou para lograr, direta ou indiretamente, qualquer proveito (SÃO PAULO, 1968).

Tais preceitos se repetem na Lei 8.112/1990 (Estatuto dos Servidores Públicos da União, das autarquias e das fundações públicas), acrescentando-se dentre outras proibições a estampada no inciso XII do artigo 117 que se refere ao recebimento de propina, comissão, presente ou vantagem de qualquer espécie em razão de suas atribuições (BRASIL, 1990).

$\mathrm{Na}$ Administração Pública Indireta se destacam alguns fundamentos de conformidade, como na Lei 13.303, de 30 de junho de 2016, que dispõe sobre o estatuto jurídico da empresa pública, da sociedade de economia mista e de suas subsidiárias (BRASIL, 2016). No artigo $6^{\circ}$ 
confere a tais entes o dever de observarem regras de governança corporativa, de transparência e de estruturas, práticas de gestão e riscos bem como de controle interno, composição da administração e, havendo acionistas, mecanismos para a sua proteção. Corrobora-se dita ideologia em seu artigo $9^{\circ}$ na medida em que assevera a necessidade de adoção de regras de estruturas e práticas de gestão de riscos que abarquem ação dos administradores e empregados, através de controle interno corriqueiro, verificação do cumprimento de obrigações e gestão de riscos, bem como auditoria interna. Tais medidas visam estabelecer padrões desejáveis de confiança organizacional pautado em práticas éticas, seguras e de confiabilidade de mercado.

Outro destaque foi o advento da Lei 13.848, de 25 de junho de 2019, que cuida acerca da gestão, organização, processo decisório e controle social das agências reguladoras. Seguindo a grande onda moral de práticas responsáveis, o artigo $3^{\circ}, \S 3^{\circ}$ do encartado em apreço dispõe quanto ao dever de adoção por tais entes de práticas de gestão de riscos e controle interno, além de elaborar e divulgar programa de integridade visando a promoção do cumprimento de medidas e ações institucionais que se destinem à prevenção, detecção, punição e remediação de fraudes e atos de corrupção (BRASIL, 2019).

Oliva e Silva (2018, p. 2711) lembram ainda que não há um modelo de compliance que possa ser adotado por toda e qualquer pessoa jurídica, já que se trata de um sistema de prevenção de riscos e de respeito à legalidade a que estão, cada qual, afetos às suas correspondentes atribuições, com características e especificidades próprias. O que possibilita a adoção do modelo que mais perfeitamente cumpra o programa proposto, "que melhor se adeque às suas particularidades, desde que seja efetivo e atenda ao objetivo primordial de efetivamente evitar infrações à ordem jurídica e de, uma vez verificadas, contribuir para sua pronta reparação", retornando ao status de normalidade anterior. A finalidade precípua de prevenção à fraude, com o emprego de condutas estimulantes de diminuição de riscos da atividade "tendo por função primordial evitar a ocorrência de violações às normas legais aplicáveis, bem como ao Código de Ética próprio de cada pessoa jurídica." (OLIVA; SILVA, 2018, p. 2719).

É plenamente possível o emprego da técnica de compliance na seara trabalhista, como fator gestor de riscos, auditorias, implantação de canais de denúncia e regulamentos internos. França $(2018$, p. 148) sugestiona ainda a possibilidade de aproveitamento de ideias extravagantes "facilitadoras das relações corporativas, como a know your costumer (conheça seu cliente/parceiro) e a know your employee (conheça seu funcionário)", favorecendo o cumprimento de demandas normativas institucionais, respeito à legislação correlata, evitando-se desavenças de ordem interna e prevenção de demandas judiciais, incorporando valores e praxe ética. Num ambiente corporativo cada vez mais competitivo o compliance passa a ser estratégia não somente tendente à obtenção de ganhos de valores, contribuindo cada vez mais à própria sobrevivência da organização no mercado concorrencial (COIMBRA; MANZI, 2010, p. 5).

França (2018,p. 155) salienta que para a aplicação de um programa em ambiente trabalhista é de grande relevância inicialmente proceder a um levantamento histórico da empresa para verificar a existência de eventual infração outrora cometida, determinando-se o contexto normativo a que 
está inserida, analisando-se eventuais riscos, condutas de seus funcionários, elaborando políticas institucionais e regras aos seus colaboradores. Aqui, a importância de treinamento dos trabalhadores voltados às práticas de conformismo instituído por cada empresa na prevenção de riscos.

A noção inovada do compliance extrapola as medidas meramente anticorrupção estampadas na Lei 12.846/2013, tomando dimensões maiores, incorporando inclusive aplicação na esfera ambiental. Exemplo disso foi a criação do selo verde como indicador das relações de consumo que motivou um grande número de empresas a adotarem posturas sob a ótica do desenvolvimento sustentável; ademais a sustentabilidade é fator preponderante à prosperidade e elevação do grau de confiabilidade empresarial, um diferencial positivo no mercado concorrencial no comprometimento corporativo com políticas públicas.

É possível identificar técnicas de compliance no plano ambiental desde 1981, quando da Lei 6.938/81 que instituiu a Política Nacional do Meio Ambiente, visando traçar objetivos voltados à preservação, melhoria e recuperação ambiental em coadunação ao desenvolvimento socioeconômico com base fundamental da segurança nacional e dignidade da pessoal humana (BRASIL, 1981).

$\mathrm{O}$ artigo $4^{\circ}$, inciso I assevera que a Política Nacional visará o estabelecimento de mecanismos de compatibilização do desenvolvimento econômico-social com a preservação da qualidade ambiental e equilíbrio ecológico, impondo àquele que polui ou emprega tomadas predatórias a obrigação de indenizar ou recuperar os danos causados, como também ao usuário da contribuição pela utilização de recursos ambientais com fins econômicos (artigo $4^{\text {o }}$, inciso VII). Referida lei alcança não somente as atividades empresariais decorrentes da vida pública, mas as praticadas na esfera puramente privada, sendo conduta recepcionada pela vigente Carta Política, no seu artigo 225.

Segal $(2018$, p. 4) ressalta que em se tratando do compliance ambiental "o mercado tende a exigir cada vez mais condutas éticas, em consonância com normas vigentes, para a consolidação de um novo comportamento por parte das empresas, que devem buscar lucratividade de forma sustentável", na condução de seus interesses, com negócios focando desenvolvimento econômico e socioambiental. Argenti (apud MANZI, 2008, p. 39) esclarece que vários são os inconvenientes empresariais em caso de inobservância de normas que eventualmente causem danos ao meio ambiente; além de riscos operacionais, de ordem jurídica ou financeira, a reputação organizacional frente ao mercado pode ser afetada negativamente, seja em face dos consumidores, de seus acionistas, fornecedores e demais clientes em potencial, ainda mais diante de um contexto informacional tão diligente.

Segal $(2018$, p. 8) ressalta também a possibilidade de responsabilização de pessoas físicas e jurídicas em caso de concorrência a práticas lesivas dessa monta; reportando-se ao artigo $2^{\circ}$ da Lei 9.605/1998 (Lei dos Crimes Ambientais) onde disciplina que aquele que de qualquer forma concorra para a prática dos crimes ali previstos incidirá nas penas cominadas na medida de sua culpabilidade, alcançando diretor, administrador, membro de conselho e de órgão técnico, auditor, gerente, preposto ou mandatário de pessoa jurídica que, tendo conhecimento acerca da conduta 
criminosa, deixa de impedir a ocorrência quando, a tempo, poderia agir para evitá-la. Frise-se a possibilidade de desconsideração de personalidade jurídica, alcançando as pessoas físicas, intitulada no correspondente artigo $3^{\circ}$, parágrafo único, sempre que for incluído obstáculo ao ressarcimento dos prejuízos causados (BRASIL, 1998a).

Richupan (1984, p.38) levanta o infeliz fenômeno mundialmente conhecido em terras onde se habitam os impostos, a sonegação fiscal; que em alto grau é capaz de reduzir "acentuadamente o valor dos incentivos fiscais e afetar o comportamento da alocação de recursos; criar tendências artificiais nos indicadores econômicos, o que pode acarretar respostas políticas inadequadas", inclusive retardar as tentativas de monetizar economias em países em fase de desenvolvimento, afetando indiscutivelmente a distribuição de renda.

Diante dessa situação, Vitalis (2019) salienta ser imprescindível à consecução de política fiscal adequada aquela que seja hábil de identificar mecanismos voltados à promoção efetiva do comportamento do compliance, na regulação do cumprimento da legislação tributária e, por conseguinte, ao cumprimento das obrigações fiscais correspondentes.

Franzoni (1998) elenca três fatores ligados ao cumprimento do compliance fiscal, sendo eles: a correta declaração sobre a renda tributável, o cálculo correto do passivo e a entrega tempestiva da declaração, acrescentando que a grande problemática está justamente envolta ao primeiro dos fatores. No âmbito fiscal a conformidade se torna bastante importante na medida em que se uma empresa não está em dia com o Fisco, sujeita-se a um emaranhado de sanções, imbuindo-se, assim, da prerrogativa de garantir a redução de riscos, diminuição de custos administrativos com afazeres associados à geração de ônus tributário e arrefecimento de carga tributária sem métodos de sonegação. Considerando que no Brasil há volúveis alterações fiscais cotidianamente, implementar o compliance fiscal no âmbito empresarial pode funcionar positivamente à prevenção de sanções em decorrência de erros de cálculos, atrasos na entrega ou inadimplência tributária. A formação de grupo específico de atualização e monitoramento, bem como o emprego de tecnologias correlatas, inserem-se num plano interessante de política integrativa e de medidas preventivas.

Percorrer em caminhos do non compliance fiscal pode refletir negativamente à imagem organizacional, apresentando pendências perante o Fisco, o que implica em redução do grau de confiança e de credibilidade com pares, inclusive instituições bancárias. Por outro lado, empresas com liquidez ganham forças para novas relações, são beneficiadas com linhas de créditos com juros menores, destacando-se em campos mais prósperos à própria ascensão.

\section{COMPLIANCE FISCAL, PLANEJAMENTO TRIBUTÁRIO E EFICIÊNCIA}

Diante de um sistema tributário brasileiro complexo, amplo e dinâmico, o planejamento tributário passou a atingir um grau de importância cada vez maior no âmbito empresarial. Alinhados ao compliance fiscal e considerando o peso que a carga tributária move em face das atividades econômicas e respectivos resultados, analisar os encargos devidos e identificar as maneiras para otimizar os custos nessa seara, tornou-se fator imprescindível à minimização de impactos negativos 
ao funcionamento das empresas, com reflexos diretos de suas receitas.

Maggi (2009, p. 56) ressalta que buscar por procedimentos lícitos de redução de pagamento de tributos, atentando-se a todo instante às mudanças legislativas, torna-se imprescindível à potencialização de lucros empresariais, à manutenção dos negócios e melhorias dos níveis de empregabilidade. Siqueira, Cury e Gomes (2011, p. 185) esclarece que diante de um mercado cada vez mais competitivo, reduzir custos tem se tornado uma necessidade constante e no caso dos tributos "o acompanhamento é algo que se impõe de forma ainda mais premente no que tange aos custos tributários, dado seu fortíssimo incremento nos últimos anos e sua característica de não gerar benefícios diretos às organizações", colocando a contabilidade tributária como forte aliada ao cumprimento de tais exigências uma vez que são inerentes a essa atividade o conjunto de operações que levam à redução de ônus tributário, cálculo do montante devido, dos pagamentos e recolhimentos, possibilitando com isso um patamar mais elevado de rentabilidade e concorrência.

Planificar medidas e minimizar despesas está intimamente ligada à conceituação basilar da eficiência de dispêndios; Latorraca (2000, p. 37) ainda acrescenta que comumente se denomina planejamento tributário o trabalho das empresas que "desenvolvendo-se de forma estritamente preventiva, projeta os atos e fatos administrativos com o objetivo de informar quais os ônus tributários em cada uma das opções legais disponíveis", tendo como objeto a economia tributária do qual deve o administrator observar, percorrendo de forma a evitar, sempre que for possível, o procedimento de maior onerosidade. Nas lições de Borges (2000, p. 55), esse planejamento tem por escopo, dentro do contexto empreendedor, a busca pelo "emprego de estruturas e formas jurídicas capazes de bloquear a concretização da hipótese de incidência tributária ou, então, de fazer com que sua materialidade ocorra na medida ou no tempo que lhe sejam mais propícios"; técnicas tais voltadas à exclusão, redução ou adiamento de encargos tributários.

Considera-se, assim, dentro do escopo ético e de comprometimento empresarial com os correspondentes encargos, a ideologia de compliance no engajamento de planos operacionais com técnicas juridicamente hígidas, prevenindo a ocorrência de novos ônus, por vezes, desnecessário à realização das atividades com alcance de resultados idênticos, embora praticados de maneiras inteligentes. Vale mencionar que tais mecanismos não remontam às ideias corruptivas tributárias encabeçadas nos artigos 71, 72 e 73 da Lei 4.502/1964 (BRASIL, 1964) ${ }^{2}$, uma vez que o que se pretende não é o esquivo das obrigações por fatos já realizados, mas sim a prevenção que não ocorra a incidência material tributável nas ações de produção da atividade empresarial, permitindo que seus agentes possam recorrer preferencialmente, antes da ocorrência do fato gerador, a procedimentos autorizados por Lei que impliquem na redução ou diferimento do impacto fiscal.

2 Art . 71. Sonegação é toda ação ou omissão dolosa tendente a impedir ou retardar, total ou parcialmente, o conhecimento por parte da autoridade fazendária:

I - da ocorrência do fato gerador da obrigação tributária principal, sua natureza ou circunstâncias materiais;

II - das condições pessoais de contribuinte, suscetíveis de afetar a obrigação tributária principal ou o crédito tributário correspondente.

Art . 72. Fraude é toda ação ou omissão dolosa tendente a impedir ou retardar, total ou parcialmente, a ocorrência do fato gerador da obrigação tributária principal, ou a excluir ou modificar as suas características essenciais, de modo a reduzir o montante do imposto devido a evitar ou diferir o seu pagamento.

Art . 73. Conluio é o ajuste doloso entre duas ou mais pessoas naturais ou jurídicas, visando qualquer dos efeitos referidos nos arts. 71 e 72 (BRASIL, 1964). 


\subsection{Custo dos tributos no setor privado}

Sandford (apud BERTOLUCCI; NASCIMENTO, 2002, p. 57) explica que os custos de tributos podem ser classificados em três categorias: os impostos que representam sacrifícios de renda para a arrecadação estatal, os custos de distorção por mudanças de comportamento na economia em face da existência de tributos, alterando-se preços dos produtos e, por fim, os custos dos recursos empregados para operacionalizar o sistema tributário, compreendendo aqui os recursos do poder público destinados a legislar, arrecadar, controlar e julgar questões relativas a tributos e os custos de conformidade na tributação que abrangem as pessoas físicas e jurídicas "que têm de cumprir as obrigações principais e acessórias definidas pelo Poder Público e que representam o sacrifício de recursos para atender às disposições legais".

O objetivo fundamental do planejamento fiscal é prover a economia tributária no âmbito empresarial, Lima e Duarte (2007, p. 9) acrescentam que a finalidade precípua é a redução legal de recursos repassados ao governo, proporcionando à empresa a diminuição de custos tributários o que, levando em consideração o contexto econômico vivenciado pelo mercado de produção, reputa-se importante à permanência em zona de concorrência.

As Pessoas Jurídicas são tributadas por uma das formas de apuração do Imposto de Rendas de Pessoa Jurídica (IRPJ) ou pela Contribuição Social Sobre o Lucro Líquido (CSLL), por intermédio de opção do contribuinte ou determinação legal, nas variadas modalidades disponíveis. Bisolo e Baggio (2012, p. 197) informam que para optar pela modalidade Simples Nacional o contribuinte deve ser enquadrado como microempresa (aquela que tenha auferido receita bruta igual ou inferior a 360 mil reais/ano-calendário) ou empresa de pequeno porte (aquela que tenha auferido receita bruta superior a 360 mil e menor que R\$ 3.600.000,00 no ano). Nesta dinâmica está compreendido o recolhimento mensal unificado que corresponde a um percentual sobre a receita bruta dos seguintes tributos (IRPJ, CSLL, COFINS, IPI, PIS, ICMS, ISS e CPP - parcela correspondente ao empregador).

Quanto ao lucro arbitrado, refere-se a uma forma coercitiva de apuração do IRPJ e CSLL, substituindo o lucro real ou presumido, podendo ser utilizada quando o contribuinte não possuir escrituração contábil ou fiscal. Nas lições de Fabretti (2009, p. 203) a autoridade tributária poderá fixar o lucro arbitrado através de um percentual sobre a receita bruta, quando conhecida, ou baseado no valor do ativo, do capital social, do patrimônio líquido, da folha de pagamento de empregados, das compras, do aluguel das instalações ou do lucro líquido auferido nos anoscalendários anteriores.

No que respeita o lucro presumido, nos moldes do artigo 13 da Lei 9.718/1998 (BRASIL, 1998b), com alteração dada pela Lei $12.814 / 2013^{3}$, reveste-se como meio alternativo de tributação

3 Art. 13. A pessoa jurídica cuja receita bruta total no ano-calendário anterior tenha sido igual ou inferior a R\$ 78.000.000,00 (setenta e oito milhões de reais) ou a $\mathrm{R} \$ 6.500 .000,00$ (seis milhões e quinhentos mil reais) multiplicado pelo número de meses de atividade do ano-calendário anterior, quando inferior a 12 (doze) meses, poderá optar pelo regime de tributação com base no lucro presumido. (Redação dada pela Lei $n^{\circ} 12.814$, de 2013)

$\S 1$ 으 A opção pela tributação com base no lucro presumido será definitiva em relação a todo o ano-calendário. 
às pequenas empresas até o limite da receita bruta total estabelecida legalmente, tendo por escopo a facilitação do pagamento do Imposto de Renda, uma opção mais vantajosa por presunção de lucro ao invés da lucratividade real; com pagamentos de impostos trimestrais, encerrados nos dias 31 de março, 30 de junho, 30 de setembro e 31 de dezembro de cada ano-calendário.

Lizote e Lana (2012, p. 7-10) demonstraram num estudo de caso de uma empresa de pequeno porte situada na cidade de Itajaí/SC, atuante do comércio atacadista de alimentos as diferenças econômicas e os impactos tributários na escolha das modalidades de tributação disponíveis. A opção tributária em 2010 foi pelo Simples Nacional e 100\% das compras de São Paulo com vendas totais para o Estado catarinense.

Auxiliados por sócios da empresa e contadores, elaboraram estimativas para o exercício seguinte com base no lucro presumido, ocasião em que foi identificada que a tributação pela sistemática do Simples Nacional foi mais vantajosa à empresa resultando num encargo fiscal menor eis que encargos e índices de preços não haviam sofrido grandes oscilações. O mesmo foi feito pelo lucro real, ocasião em que se verificou uma redução de carga tributária refletindo em maior lucratividade para a empresa, "uma economia média de $1.62 \%$ em relação ao faturamento, representando uma economia de R \$2.479,00 ao mês", que num momento de crise pode ser fator preponderante ao enfrentamento de turbulências de mercado, garantindo-se reserva para tomadas futuras que convier à gestão empresarial.

\subsection{Minimização dos riscos e maximização da eficiência com vistas ao aumento da competitividade}

Diante de todas as vertentes abordadas sobre o compliance, agregado ao fato das exigências mercadológicas valorizarem a higidez de condutas corporativas, comprometimento institucional não somente no alinhamento da Lei e de normas internas em planejamentos estratégicos, mas também com relação à tutela de direitos sociais, aqui incluídos a preservação do meio ambiente, do respeito aos trabalhadores e nas relações empresariais com seus pares transacionais, incluídos fornecedores, terceirizados e consumidores, transparecer tais práticas, num ambiente informacional tão vultoso, dinâmico e acelerado, reputa-se fator preponderante ao sobressalto dentro no mercado competitivo.

Vello e Martinez (2014, p. 119) informam que no Brasil, conforme dados divulgados pelo Instituto Brasileiro de Planejamento Tributário, houve um aumento significativo da carga tributária entre os anos de 2000 e 2010 , subindo de "30,03\% para o representativo valor de 35,04\% do Produto Interno Bruto (PIB). O aumento nominal da arrecadação em 2010, em relação ao ano anterior, foi recorde, alcançando 17,80\%". Além disso, multas por danos ambientais e indenizações também nas esferas trabalhistas, práticas de corrupção interna impactam não somente o orçamento empresarial, mas a possibilidade de desenvolvimento institucional, investimento em melhorias e

\footnotetext{
$\S 2$ ㅇ Relativamente aos limites estabelecidos neste artigo, a receita bruta auferida no ano anterior será considerada segundo o regime de competência ou de caixa, observado o critério adotado pela pessoa jurídica, caso tenha, naquele ano, optado pela tributação com base no lucro presumido (BRASIL, 2013).
} 
paridade competitiva.

Macedo (2018, p. 16) explica que os riscos podem ser definidos como "eventos futuros incertos com potenciais impactos em fluxos de caixa, rentabilidade, retorno para o acionista, perda de mercado e reputação", essencialmente incorporam-se como sinal de perigo, insucesso, cuja ocorrência independe da vontade inicialmente traçada pelas empresas. O grande desafio de gestão é justamente identificar até que ponto tais incertezas são aceitáveis, definindo a extensão que tais barreiras podem assumir em face dos objetivos empresariais e influência na agregação de valores futuros.

Diante desses fatores a serem considerados, o compliance assume importante papel à minimização de riscos, maximizando as metas empresariais de maior produtividade, aumento de receita, lucratividade, propiciando a instalação de um ambiente favorável ao alcance de suas metas e destaque mercadológico, "o mercado atual exige empresas competitivas que saibam se planejar com eficiência.”. (VELLO; MARTINEZ, 2014, p. 119). O controle interno é outro fator relevante à eficiência da empresa e consequente destaque competitivo, Sá (2002, p. 106) salienta que a prática avaliativa do controle corporativo "é, pois, o processo auxiliar de auditoria através do qual medimos a capacidade dos meios utilizados por uma empresa ou instituição para proteger seu patrimônio e os objetivos deste".

Scott (1992. p. 160) entende que as organizações, no momento atual, "não existem e competem como unidades individuais autônomas, mas como membros de amplos sistemas". É justamente esse fato que indica a necessidade de concepção do compliance como instrumento sistêmico de ganho de competitividade, sendo assim fundamental para as organizações.

Slack, Brandon-Jones e Johnston (1997) definem cinco fatores que contribuem para a vantagem competitiva das organizações: confiabilidade; custo; flexibilidade, qualidade e velocidade. Esses fatores seriam fundamentais para que as organizações atingissem graus de competitividade satisfatórios. Observa-se assim que a questão da confiabilidade encontra-se umbilicalmente relacionada a implementação de programas de conformidade.

Sobre o tema, destacam Darlan José Roman et al. (2012, p. 32):

$\mathrm{O}$ estudo dos fatores de competitividade é importante para que se consiga o método adequado para o desenvolvimento de produtos e processos, com a utilização das melhores práticas para excelência em custos, em qualidade e em prazo, e para que se possa capturar as necessidades dos consumidores, para que estas sejam atendidas via o produto oferecido. A observação dos fatores críticos é indispensável para que a organização consiga desempenhos melhores, atendendo, assim, às exigências de sua missão.

Assim, não se pode duvidar que para a implementação de um programa de conformidade empresarial, deve haver estudo dos fatores de competitividade, de forma a alcançar um melhor foco nas práticas que devem ser adotadas, observando os fatores críticos particulares de cada organização. 


\section{CONCLUSÃO}

Diante todos os apontamentos discorridos no presente estudo, pode-se concluir que a corrupção é prática bastante antiga e já há tempos é discutida e repreendida com inúmeras medidas normativo-legais visando propiciar um ambiente de higidez e boas práticas.

Nota-se que no domínio corporativo, condutas afetadas por mecanismos fraudulentos podem refletir negativamente nos empreendimentos econômicos, agravado diante de um ambiente informacional tão célere e impiedoso, em que o mercado consumidor sopesa e exige valores primordiais que proporcionem segurança jurídica e comprometimento aos preceitos legais, responsabilidade social e favorecimento à promoção de políticas públicas.

Verifica-se que o compliance, embora revestido sob outros preceitos de ordem ética no ordenamento jurídico, ganhou corpo há pouco tempo, relativamente, definindo-se e ocupando espaço exclusivo nos mais diversos setores organizacionais, seja público ou privado, apesar de ser mais destacado no âmbito empresarial; hoje é fundamental.

É possível afirmar que em berço corporativo, o compliance assumiu papel preponderante ao resguardo das empresas contra riscos da seara trabalhista, ambiental e administrativa, sendo capaz de minimizar gastos desnecessários, prevenir empreendedores de multas, ações judiciais e indenizações por práticas eventualmente realizadas por seus pares, mas que não estejam em conformidade aos ditames norteadores institucionais.

O planejamento tributário, quando alinhado ao compliance fiscal, potencializa a capacidade empreendedora, favorecendo empresas ao aumento da competitividade, maior economia de suas receitas e reserva de caixa que pode ser destinado tanto à segurança corporativa em tempos de mercado conturbado, como à realização de novos investimentos e consequente crescimento e aprimoramento das atividades desenvolvidas.

Conclui-se, por derradeiro, que a prática da conformidade, em especial o compliance fiscal, figura-se instrumento fundamental à minimização de riscos e aumento da competitividade, inclusive à recuperação da opinião externa e comprometimento do mercado nacional no cumprimento de regramentos e confiabilidade de ambiente pautado na integridade e na segurança de investimentos, com resgate da economia e atratividade de novos capitais.

\section{REFERÊNCIAS}

ABREU JUNIOR, Rudinei Machado de. Lei anticorrupção brasileira: o impacto nas estruturas de governança corporativa das instituições financeiras do Estado do Rio Grande do Norte. 2015. Dissertação (Mestrado em Administração) - Universidade Federal de Santa Catarina, UFSC, Florianópolis, 2015.

ASSI, Marcos. Compliance como implementar. São Paulo: Jurídicos Trevisan, 2018. 
BERTOLUCCI, Aldo V.; NASCIMENTO, Diogo Toledo do. Quanto custa pagar tributo? Revista Contabilidade e Finanças - USP, São Paulo, v. 13, n. 29. p. 55-67, 2002. Disponível em: http://www.revistas.usp.br/rcf/article/view/34074/36806. Acesso em: 24 out. 2019.

BISOLO, Tanise; BAGGIO, Daniel Knebel. Planejamento tributário: estudo do regime tributário menos oneroso para indústria. Revista de Administração IMED, Passo Fundo, v. 2, n. 3. p. 195-206, 2012. Disponível em: https://seer.imed.edu.br/index.php/raimed/article/view/250. Acesso em: 24 out. 2019.

BORGES, Humberto Bonavides. Gerência de impostos: IPI, ICMS e ISS. 3. ed. São Paulo: Atlas, 2000.

BRASIL. Lei 12.846, de $1^{0}$ de agosto de 2013. Dispõe sobre a responsabilização administrativa e civil de pessoas jurídicas pela prática de atos contra a administração pública, nacional ou estrangeira, e dá outras providências. Brasília: Presidência da República, 2013. Disponível em: http://www.planalto.gov.br/ccivil_03/_Ato2011-2014/2013/Lei/L12846.htm. Acesso em: 24 out. 2019.

BRASIL. Lei 13.303, de 30 de junho de 2016. Dispõe sobre o estatuto jurídico da empresa pública, da sociedade de economia mista e de suas subsidiárias, no âmbito da União, dos Estados, do Distrito Federal e dos Municípios. Disponível em: http://www.planalto.gov.br/ ccivil_03/_ato2015-2018/2016/lei/113303.htm. Acesso em: 24 out. 2019.

BRASIL. Lei 13.848, de 25 de junho de 2019. Dispõe sobre a gestão, a organização, o processo decisório e o controle social das agências reguladoras [...]. Brasília: Presidência da República, 2019. Disponível em: http://www.planalto.gov.br/ccivil_03/_ato2019-2022/2019/1ei/L13848.htm. Acesso em: 24 out. 2019.

BRASIL. Lei 4.502, de 30 de novembro de 1964. Dispõe sobre o Imposto de Consumo e reorganiza a Diretoria de Rendas Internas. Brasília: Presidência da República, 1964. Disponível em: http://www.planalto.gov.br/ccivil_03/LEIS/L4502.htm. Acesso em: 24 out. 2019.

BRASIL. Lei 8.112, de 11 de dezembro de 1990. Dispõe sobre o regime jurídico dos servidores públicos civis da União, das autarquias e das fundações públicas federais. Brasília: Presidência da República, 1990. Disponível em: http://www.planalto.gov.br/ccivil_03/leis/18112cons.htm. Acesso em: 24 out. 2019.

BRASIL. Lei 9.605, de 12 de fevereiro de 1998. Dispõe sobre as sanções penais e administrativas derivadas de condutas e atividades lesivas ao meio ambiente, e dá outras providências. Brasília: Presidência da República, 1998a. Disponível em: http://www.planalto. gov.br/ccivil_03/leis/19605.htm. Acesso em: 24 out. 2019.

BRASIL. Lei 9.718, de 27 de novembro de 1998. Altera a Legislação Tributária Federal. Brasília: Presidência da República, 1998b. Disponível em: http://www.planalto.gov.br/ccivil_03/ LEIS/L9718compilada.htm. Acesso em: 24 out. 2019.

BRASIL. Lei 9.938, de 31 de agosto de 1981. Dispõe sobre a Política Nacional do Meio Ambiente, seus fins e mecanismos de formulação e aplicação, e dá outras providências. Brasília: Presidência da República, 1981. Disponível em: http://www.planalto.gov.br/ccivil_03/LEIS/ L6938.htm. Acesso em: 24 out. 2019. 
COIMBRA, Marcelo de Aguiar; MANZI, Vanessa Alessi. Manual de compliance: preservando a boa governança e a integridade das organizações. São Paulo: Atlas, 2010.

FABRETTI, Láudio Camargo. Contabilidade tributária. 11. ed. São Paulo: Atlas. 2009.

FERREIRA FILHO, Manoel Gonçalves. A corrupção como fenômeno social e político. Revista de Direito Administrativo, Rio de Janeiro, v. 185, p. 1-18, jul-set. 1991. Disponível em: http:// bibliotecadigital.fgv.br/ojs/index.php/rda/article/view/44482/47693. Acesso em: 24 out. 2019.

FERREIRA, Bráulio Cavalcanti QUEIROZ, Bruna Pamplona de; GONÇALVES, Everton das Neves. Análise econômica do direito e o compliance: apreciação jurídico-econômica dos programas de conformidade e dos custos de prevenção. Economic Analysis of Law Review, Brasília, v. 9, n. 1, p. 259-276, jan-abr. 2018. Disponível em: https://portalrevistas.ucb.br/index. php/EALR/article/view/8455. Acesso em: 24 out. 2019.

FRANÇA, Jaíne Gouveia Pereira. O compliance trabalhista como ferramenta para evitar ações judiciais. Revice: Revista de Ciências do Estado, Belo Horizonte, v. 3, n. 1, p. 147-169. jan-jul. 2018. Disponível em: https://periodicos.ufmg.br/index.php/revice/article/view/5090. Acesso em: 24 out. 2019.

FRANZONI, Luigi Alberto. Tax evasion and tax compliance. Sep. 1998. Disponível em: https://papers.ssrn.com/sol3/papers.cfm?abstract_id=137430. Acesso em: 24 out. 2019.

GABAN, Eduardo Molan; DOMINGUES, Juliana Oliveira. Direito antitruste. 4. ed. São Paulo: Saraiva, 2016.

GABARDO, Emerson; MORETTINI E CASTELLA, Gabriel. A nova lei anticorrupção e a importância do compliance para as empresas que se relacionam com a Administração Pública. A \& C: Revista de Direito Administrativo \& Constitucional, Belo Horizonte, v. 60, p. 129-147, abr-jun. 2015. Disponível em: https://www.editoraforum.com.br/wp-content/uploads/2015/08/ lei-anticorrupcao-compliance.pdf. Acesso em: 24 out. 2019.

HAYASHI, Felipe Eduardo Hideo. Medidas transnacionais de combate à corrupção como meta de desenvolvimento globalizado sustentável. 2014. Dissertação (Mestrado em Direito) Pontifícia Universidade Católica do Paraná, PUC-PR. Curitiba, 2014.

LATORRACA, Nilton. Direito tributário:imposto de renda das empresas. 15. ed. São Paulo: Atlas, 2000.

LIMA, Francineide Borges; DUARTE, Ana Maria da Paixão. Planejamento tributário: instrumento empresarial de estratégia competitiva. Qualitas Revista Eletrônica, Campina Grande, v. 6, n. 1. p. 1-24. 2007. Disponível em: http://revista.uepb.edu.br/index.php/qualitas/ article/view/106. Acesso em: 24 out. 2019.

LIZOTE, Suzete Antonieta; LANA, Jeferson. A importância do planejamento tributário para a lícita redução dos tributos e otimização dos lucros. In: SIMPÓSIO DE EXCELÊNCIA EM GESTÃO E TECNOLOGIA- SEGT, 9., 2012, Rio de Janeiro. Anais [...]. Rio de janeiro: SEGT, 2012. Disponível em: https://www.aedb.br/seget/arquivos/artigos12/1021676.pdf. Acesso em: 24 out. 2019.

MACEDO, Emerson Lima de. Controles internos: percepções de gestores de negócio e de 
compliance sobre sua utilização como instrumento de competitividade. 2018. Dissertação (Mestrado em Gestão para Competitividade) - Fundação Getúlio Vargas, São Paulo, 2018.

MAGALHÃES, João Marcelo Rego. Aspectos relevantes da lei anticorrupção empresarial brasileira (Lei $n^{\circ}$ 12.846/2013). Revista Controle: Doutrinas e Artigos, Ceará, v. 11, n. 11, p. 24-46. 2013. Disponível em: https://dialnet.unirioja.es/servlet/articulo?codigo=6167712. Acesso em: 24 out. 2019.

MAGGI, Luiz. Planejamento contábil e tributário. Belo Horizonte: Fumarc, 2009.

MANZI, Vanessa Alessi. Compliance no Brasil: consolidação e perspectivas. São Paulo: 2008.

MARQUES, Carolina Barbosa. Lei anticorrupção e seus reflexos práticos para empresas exportadoras, terceirizadas e órgãos públicos. In: CONIC-SEMESP, 15., 2015, Ribeirão Preto. Anais [...]. Ribeirão Preto: Universidade de Ribeirão Preto, 2015. Disponível em: http://www. conic-semesp.org.br/anais/files/2015/trabalho-1000019134.pdf. Acesso em: 24 out. 2019.

NOONAN JUNIOR, John T. Subornos. Tradução de Elsa Martins. Rio de Janeiro: Editora Bertrand Brasil S.A., 1989.

OLIVA, Milena Donato; SILVA, Rodrigo da Guia. Notas sobre o compliance no direito brasileiro. Quaestio Iuris, Rio de Janeiro, v. 11, n. 4, p. 2708-2729, 2018. Disponível em: https://www.e-publicacoes.uerj.br/index.php/quaestioiuris/article/view/33843. Acesso em: 24 out. 2019.

RICHUPAN, Somchai. Mensuração da sonegação fiscal. Finanças e Desenvolvimento, Belo Horizonte, v. 4, n. 4, p. 38-40, 1984. Disponível em: http://bibliotecadigital.fgv.br/ojs/index.php/ fdesenvolvimento/article/view/62446/60565. Acesso em: 24 out. 2019.

ROMAN, Darlan José; PIANA, Janaina; LOZANO, Marie Anne Stival Pereira e Leal; MELLO, Nelson Ruben de; ERDMANN, Rolf Hermann. Fatores de competitividade organizacional. BBR - Brazilian Business Review, Vitória, v. 9, n. 1, p. 27-46, 2012.

SÁ, A. Lopes de. Curso de auditoria. 10. ed. São Paulo: Atlas, 2002.

SANTOS, Renato Almeida dos. Compliance como ferramenta de mitigação e prevenção da fraude organizacional. 2011. Dissertação (Mestrado em Administração) - Pontifícia Universidade Católica de São Paulo, PUC-SP, São Paulo, 2011.

SÃO PAULO. Assembleia Legislativa. Lei 10.261/68, de 28 de outubro de 1968. Dispõe sobre o Estatuto dos Funcionários Públicos Civis do Estado. Disponível em: https://www.al.sp.gov.br/ repositorio/legislacao/lei/1968/lei-10261-28.10.1968.html. Acesso em: 24 out. 2019.

SCOTT, W. Richard. The organization of environments: network, cultural, and historical elements. In: MEYER John W.; SCOTT W. Richard (ed.). Organizational environments: ritual and rationality. London: Sage Publications, 1992.

SEGAL, Robert Lee. Compliance ambiental na gestão empresarial: distinções e conexões entre compliance e auditoria de conformidade legal. Reasu: Revista Eletrônica de Administração da Universidade de Santa Úrsula, Rio de Janeiro, v. 3, n. 1, p. 1-22, 2018. Disponível em: http:// revistas.icesp.br/index.php/REASU/article/view/389. Acesso em: 24 out. 2019. 
SIQUEIRA, Eurípedes Bastos; CURY, Lacordaire Kemel Pimenta; GOMES, Thiago

Simões. Planejamento tributário. Revista CEPPG, Catalão, v. 2, n. 25, p. 184-196, 2011. Disponível em: http://www.portalcatalao.com/painel_clientes/cesuc/painel/arquivos/ upload/ temp/51c23e8670bb3aeef7da564aa767d33b.pdf. Acesso em: 24 out. 2019.

SLACK, Nigel; BRANDON-JONES, Alistair; JOHNSTON, Robert. Administração da produção. São Paulo: Atlas, 1997.

VELLO, André, MARTINEZ, Antonio Lopo. Planejamento tributário eficiente: uma análise de sua relação com o risco de mercado. Revista Contemporânea de Contabilidade - UFSC, Florianópolis, v. 11, n. 23. p. 117-140, maio/ago. 2014. Disponível em: https://periodicos.ufsc.br/ index.php/contabilidade/article/view/2175-8069.2014v11n23p117. Acesso em: 24 out. 2019.

VITALIS, Aline. Compliance fiscal e regulação fiscal cooperativa. Revista de Direito GV, São Paulo, v. 15, n. 1, 2019. Disponível em: http://www.scielo.br/scielo.php?pid=S180824322019000100202\&script=sci_arttext\&tlng=pt. Acesso em: 24 out. 2019.

Como Citar: OLIVEIRA, Bruno Bastos de. GERMINARI, Jefferson Patrick. Compliance fiscal: diminuição de riscos e aumento de competitividade no mundo corporativo. Scientia Iuris. Londrina, v.24, n.1, p. 78-98, março 2020. DOI 10.5433/21788189.2020v24n1p78. ISSN 21788189.

Recebido em 20/11/2019

Aprovado em 14/02/2020 